\title{
Duke University School of Nursing's Impact on Nursing and Midwifery Education in Rwanda
}

\author{
Patricia Moreland ${ }^{1}$, Isabelle Soule ${ }^{2}$, Linda Vanhook ${ }^{3}$, Linda Baxter ${ }^{4}$, Claire McKinley Yoder ${ }^{5}$, \\ Michael V. Relf ${ }^{6}$ \\ ${ }^{1}$ University of Rwanda, College of medicine and health sciences Kabgayi school of Nursing and Midwifery, \\ ${ }^{20}{ }^{2} 4$ University of Rwanda, College of medicine and health sciences Byumba School of Nursing and midwifery \\ ${ }^{3}$ University of Rwanda, College of medicine and health sciences Nyagatare School of Nursing and midwifery, \\ ${ }^{5}$ Mubima Hospital, Rwanda \\ ${ }^{6}$ Duke University
}

\section{Background}

In August, 2012, Duke University School of Nursing partnered with Rwanda's Ministry of Health to join the Rwanda Human Resources for Health Program, a seven-year initiative to increase the quantity and quality of Rwanda's health professional workforce. The purpose of this paper is to: (1) describe an educational project to promote evidence-based practice in the clinical and didactic settings; (2) to evaluate barriers to integration of best practices in the clinical setting.

\section{Description}

Evidence-based practice and the integration of research into the clinical setting were identified as priority areas in nursing education. Common causes of preventable morbidity and mortality were identified in neonatology, midwifery, pediatrics and medical-surgical areas. Current practice guidelines were evaluated and critiqued. Evidence-practice guidelines were integrated into didactic teaching emphasizing the role of the nurse in implementation of best practices. Perceived barriers to implementation of guidelines were discussed.

\section{Lessons learned}

Lack of knowledge and access to current clinical practice guidelines were identified as barriers to integration of evidence-based practice into clinical and didactic teaching. Perceived barriers in the clinical setting included perspectives of clinicians and lack of interprofessional and organizational collaboration.

\section{Conclusions}

Curriculum revision is needed to integrate evidence-based practice guidelines. Faculty support to develop innovative strategies to teach best practices in the clinical and didactic setting are suggested.

Key words: evidence-based practice, research, translation to clinical practice, Rwanda, burden of disease 